\title{
Value added tax on
}

\section{medicines in EU countries}

\author{
Vladimir Panov \\ Department of Conservative Dentistry and Oral \\ Pathology, Faculty of Dental Medicine, Medical \\ University, Varna;
}

\begin{abstract}
Value added tax (VAT) is calculated on each product, at each level, from manufacturer to retailer. Data show that in Bulgaria this tax for medicines is among the highest in the European Union - 20\%. Only in Norway, Ireland, and Denmark the values are higher.
\end{abstract}

A zero rate exists in $10 \%$ of EU member states, namely Malta, the United Kingdom, and Sweden. If we look at the changes in VAT over the last 7 years, we will notice that in 4 member states values have decreased (in the Czech Republic from 15 to $10 \%$, in Greece from 6.5 to $6 \%$, in Iceland from 25.5 to $24 \%$, and in Slovenia from 9.5 to $8.5 \%$ ), and there has been no increase recorded in any member state. Research shows that 28 out of 34 countries in Europe have lower VAT on prescription drugs than Bulgaria.

It is imperative to take measures to reduce its value in Bulgaria. This is a necessary condition for improving both the economic and health status of our population. It will be helpful to introduce a differentiated VAT rate for medicines.

Keywords: value added tax, medicines, European Union

\section{Introduction}

Value added tax (VAT) is added on every product, at every level, from producer to retailer. Data show that in Bulgaria this tax is the highest in the European Union. There is no differentiated approach to medicines compared to other products, as opposed to other European countries [1, 2]. 


\section{Aim}

The purpose of this study is to analyze information on medicines and drug rates in Bulgaria and in the other EU member states.

\section{Materials \& Methods}

A comprehensive literature review has been conducted to evaluate the application of value added tax to medicines in the European Union and Bulgaria's position in relation to VAT on prescription drugs.

\section{Results}

Value added tax first appeared in Germany in 1918. It was proposed to improve sales tax to allow for tax deduction to be paid, thus solving the problem of re-imposing sales tax. VAT is a tax paid by final users and is an alternative to direct taxes such as income tax. VAT was introduced de facto for the first time in 1954 in France. First, large French companies were subject to VAT and later all companies [5].

Only 3 country have no differentiated VAT to medicines \% compared to the Standard VAT rate \%- Bulgaria, Germany and Iceland(Tabl 1).

\begin{tabular}{|l|l|l|l|l|l|}
\hline Country & $\begin{array}{l}\text { Standard } \\
\text { VAT rate } \%\end{array}$ & $\begin{array}{l}\text { VAT to } \\
\text { medicines } \%\end{array}$ & Country & $\begin{array}{l}\text { Standard } \\
\text { VAT rate } \%\end{array}$ & $\begin{array}{l}\text { VAT to } \\
\text { medicines \% }\end{array}$ \\
\hline Austria & 20 & 10 & Ireland & 23 & $0-23$ \\
\hline Belgium & 21 & 6 & Italy & 22 & 10 \\
\hline BULGARIA & 20 & 20 & Latvia & 21 & 12 \\
\hline Croatia & 25 & 5 & Luxembourg & 17 & 3 \\
\hline Cyprus & 19 & 5 & Malta & 18 & 0 \\
\hline Czech Republic & 21 & 10 & Netherlands & 21 & 6 \\
\hline Denmark & 21 & 25 & Poland & 23 & 8 \\
\hline Estonia & 20 & 9 & Portugal & 23 & 6 \\
\hline Finland & 24 & 10 & Romania & 19 & 9 \\
\hline France & 20 & 2.1 & Slovakia & 18 & 10 \\
\hline Germany & 19 & 19 & Spain & 21 & 4 \\
\hline Greece & 24 & 6 & Sweden & 25 & 0 \\
\hline Hungary & 27 & 5 & Switzerland & 7.7 & 2.5 \\
\hline Iceland & 24 & 24 & United Kingdom & 20 & 0 \\
\hline
\end{tabular}

Tabl.1 VAT Rates on Medicine in Europe by Country (2018-EFPIA) [2].

VAT is not a direct tax. It is due to the state. It is paid by the seller in the budget, but in fact it is paid by the buyer because it is included in the final hundredth of the goods or services. VAT largely determines the 
prices of goods.

Medicine product prices are an important and fundamental issue in the field of health. Medicines are an important component of expenditure in member states health budgets. These costs are large, mainly due to the aging of the population, the aim for better diagnostics and increased costs for developing new medicines. At the same time, the regulation of drug prices will affect one of the major industrial sectors in the European economy in terms of employment, production and research and development.

\section{VAT in Bulgaria}

In Bulgaria, the introduction of VAT was provided by Decree 56 for economic activity in 1989. Article 87 (1) of the Decree states: "Companies pay value added tax, excise duty, rent tax, customs duty, profit tax and payroll tax." The tax was introduced in Bulgaria on April 1, 1994 at a rate of 18 percent. In 1996 it increased to 22 percent and in 1999 the rate was decreased to 20 percent. Ever since the introduction of the tax in 1994, the tax period has been monthly and VAT returns are submitted by the 14th of the following month.

Value added tax is the main, largest and most important source of revenue for the country. It accounts for about $1 / 2$ of all tax and social security income, followed by social security contributions of $31 \%$, excise taxes - $17 \%$, personal income tax $-11 \%$ and corporation tax - $6 \%$ of income. VAT is regarded as a tax on consumption and export of goods from the country or provision of services abroad (for EU countries - outside the community) is generally VAT exempt or the tax should be refunded. VAT is levied on imports of goods into the European Union in order for goods manufactured in the Community to be on an equal footing with such imported goods.

\section{Coordinated administration of value added tax within the EU}

Value added tax is collected at each stage of the supply chain and is made available to the tax authorities of the member state concerned and forms part of that state's revenue. A small part is provided to the European Union in the form of a fee. The coordinated administration of EU VAT is an important part of the united market. Cross-border VAT is declared in the same way as internal VAT, which facilitates the removal of border controls between member states, saving costs and reducing delays. It also simplifies the administrative work for freight forwarders. Previously, despite the Customs Union, the different VAT rates and the different VAT administration procedures have led to a great deal of administrative and financial burden on cross-border trade [3].

For individuals (not registered for VAT) who transport goods purchased while traveling in another member state, VAT is usually paid in the country where the goods were purchased, regardless of the differences in VAT rates between the two. All taxes due on distance sales are collected by the seller. However, there are a number of specific provisions for specific goods and services.

\section{European Union VAT Directive}

The purpose of the EU VAT Directive (Council Directive 2006/112 / EC of 28 November 2006 on the common system of value added tax) is to harmonize VAT in the EU and to specify that VAT rates must be within a certain range [3]. The main objectives are to harmonize legislation in the field, regulate accounting by providing a common legal accounting framework, a detailed description of invoices (Article 226) and receipts (Article 226b), regulation of accounts payable, regulation of accounts receivable, and standard definitions of national accounting and administrative conditions.

The EU VAT system is governed by a series of European Union directives, the most important of which is the Sixth VAT Directive [6]. This Directive was updated and replaced by another Directive [7] as of 1 January 2007. 


\section{Zero rate}

Some goods and services have zero VAT. This is treated as a positive tax rate of $0 \%$. Goods or services that are subject to a zero rate are considered to be subject to VAT. In the UK, examples include food, medicine, books, some modes of transport. The zero rate is not included in the Sixth EU Directive, as the minimum VAT rate across Europe is estimated to be $5 \%$. However, in some member states, the tax has zero value, especially in the UK and Ireland, as a legacy of legislation prior to their entry into the EU. These member states are given the option of continuing to apply zero tax, but they cannot add new goods or services. An EU member state may raise its internal zero rate to a higher percentage, for example, to $5 \%$ or $20 \%$. EU VAT rules do not allow the zero rate to be reversed once it has renounced it once.

Of interest is the existence of a zero rate in $10 \%$ of EU member states, namely Malta, the United Kingdom and Sweden for medicines. According to the above, if these countries raise VAT, then it will have to be at least $5 \%$, and they will not subsequently be able to return it to zero [8].

\section{VAT rates}

Different amounts of VAT apply in different EU member states. The lowest standard value for VAT in the EU is $17 \%$, although member states may apply reduced VAT rates to certain services or goods. Some goods and services must be exempt from VAT (such as medical care, postal services, credit, insurance, betting) and some other goods and services exempt from VAT but subject to the possibility of an EU member state opting to levy VAT on such supplies (such as land and certain financial services). The import tax due on exempt supplies cannot be refunded [9].

\section{EU VAT Region}

The EU VAT area is a territory consisting of the territory of all the member states of the European Union and some other countries which follow the rules of the European Union (EU) on value added tax [12]. The principle also applies to certain special taxes on products such as alcohol and tobacco.

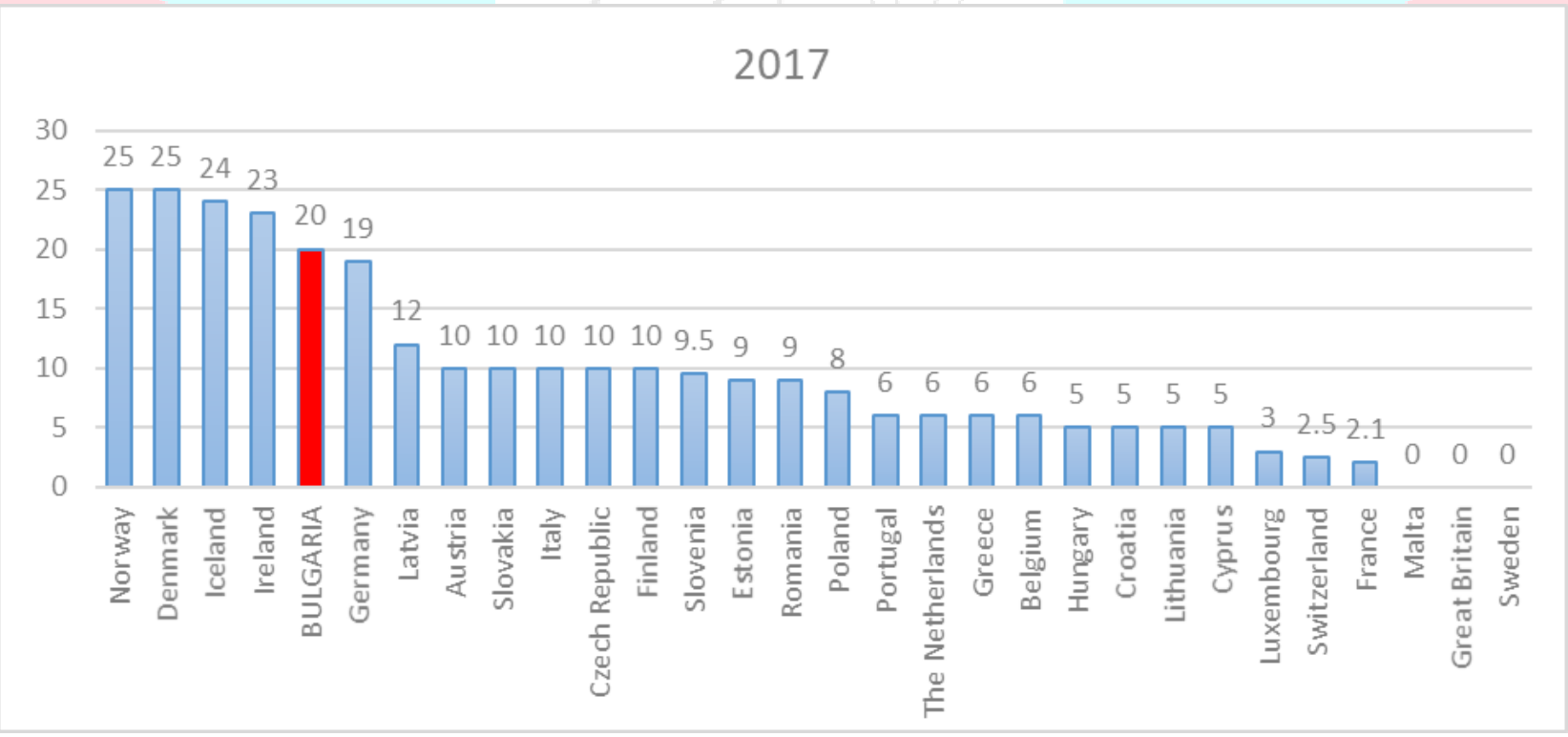

Figure 1. VAT on medicines in 2017 in the EU(\%)

Goods are considered imported or exported only if they enter or leave the area. However, the VAT rate 
varies from country to country, which is a complicating factor, especially when, for example, an Internet retailer based in one EU country sells to an EU customer in another EU country. When the goods or services are sold to a company across the border in the area, or the buyer pays VAT to the selling side of the seller, or it is possible to register the transaction as an inter-company sale without VAT being collected. If VAT is paid, the buyer cannot include it in his VAT invoices as VAT paid locally.

When goods or services are sold (and sent) to a private person across the border, the buyer usually pays VAT to the seller side and does not pay VAT in the buyer's country. However, if the annual sales of the seller of goods in the buyer's country exceed the threshold (which varies by country), the seller must charge VAT in the buyer's country. These are known as distance selling rules [14]. When a private person visits another EU country and buys goods, the seller does not have to take special action but only claim local VAT and the buyer can bring it for personal needs or gifts without restrictions.

\section{VAT on medicines in EU Member States}

If we look at the VAT rates for medicines from 2017 in the EU member states, we will notice big differences (Figure 1). In general, we can divide the member states into four groups. The first group includes 6 countries with a VAT rate on medicines of $19 \%$ to $25 \%$. This group includes countries in a good economic condition and a high level of gross domestic product, as well as a good purchasing power of the population. The only exception to this is Bulgaria, as one of the poorest EU member states.

In the second group are 10 countries with VAT from 8 to 12\%. Most of the countries in this group are from Central and Eastern Europe.In the fourth group are the countries with tax values of 6 or $5 \%$.

Malta, the UK and Sweden have a zero rate on medicines, although according to a European directive, the minimum VAT rate across Europe should be $5 \%$.

If we look at the changes in VAT over the last 7 years, we will notice that in 4 member states it has decreased (in the Czech Republic from 15 to $10 \%$, in Greece from 6.5 to $6 \%$, in Iceland from 25.5 to $24 \%$, in Slovenia from 9.5 to $8.5 \%$ ). This is a decrease in about $14 \%$ of the member state countries, with no change in the rest. The trend is to reduce the amount of this tax (Figure 2).

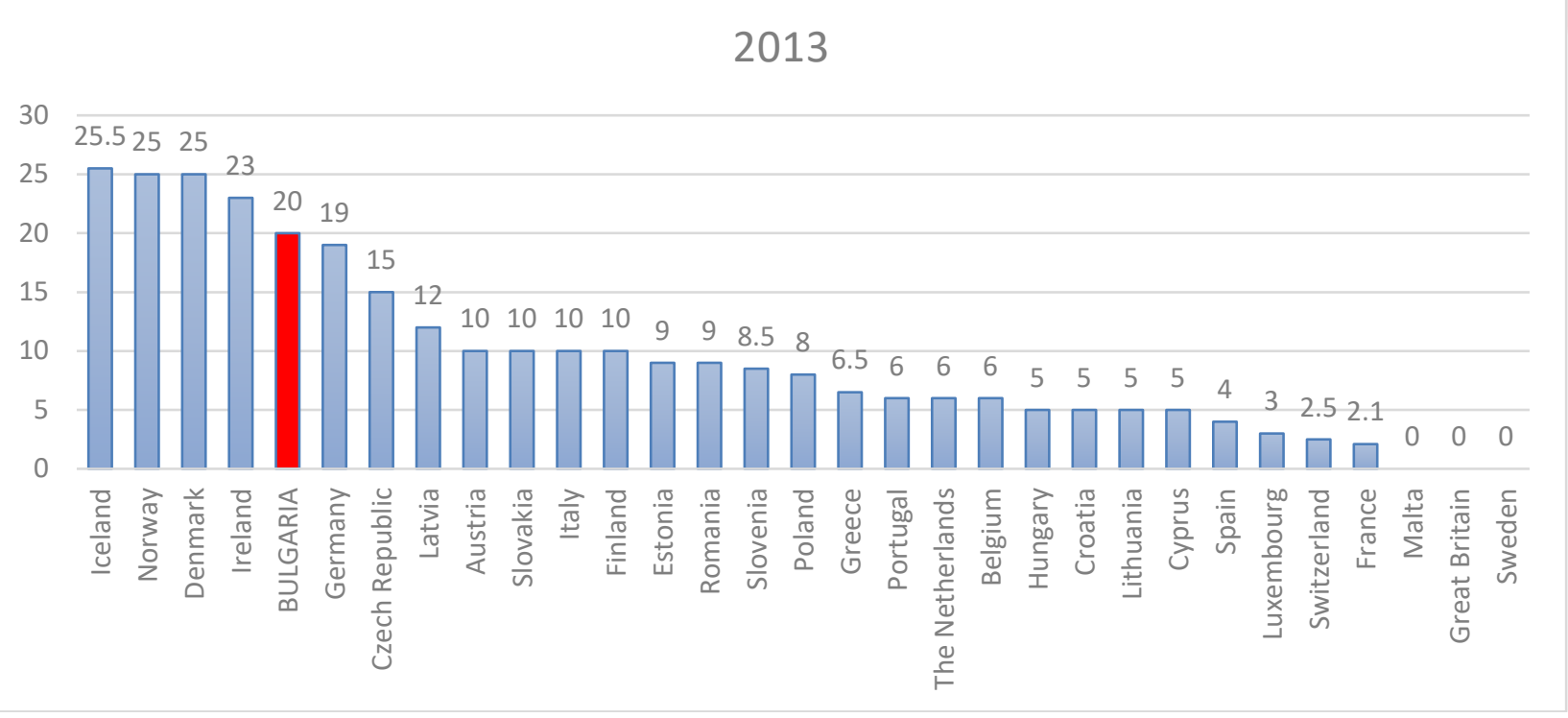

Figure 2. VAT on medicines in 2013 in the EU(\%) 


\section{VAT on medicines in Bulgaria}

The National Assembly introduced VAT in Bulgaria on medicines on January 1, 2002 in its full amount of $20 \%$. Since then, despite repeated discussions, it has not been changed. Studies show that 28 out of 34 countries in Europe have lower VAT on prescription drugs. In most EU countries, prescription drugs are subject to a lower VAT rate. Only a few countries, including Bulgaria, do not have such a lower rate. Debates on the topic have been going on for years. If VAT on medicines is lower, patient end prices will fall by between 9 and 17 percent. Calculations show that, depending on how much the rate is reduced, prescription drugs with a price of about 12 leva will become cheaper by up to 2 leva, the medicines from about 200 leva - by up to 37 leva, and the more expensive ones from about 1200 leva - will become cheaper by up to 207 leva.

Reducing the rate of prescription drugs would free up to 150 million BGN from the budget of the health fund, but would deprive the state of about 350 million BGN of VAT revenues, since this tax constitutes about one third of all revenues in the treasury. In fact, if VAT goes down, the money given by patients for prescription drugs will decrease by up to 200 million a year, which the state will not take as tax. Obviously, with such a state policy pursued, the country does not want to deprive itself of this large revenue. The report reveals periodic attempts by various authorities - economists, KP Podkrepa, political formations, NGOs, the Ombudsman, and MPs, to reduce VAT in the years since its introduction. There are also proposals to release medicines purchased from the NHIF from VAT, but in practice, nothing has been done. Actually, the payment of VAT on medicines is money returned to the budget which practically means double taxation for the population - once there is payment of health insurance and a second time VAT on the use of the service of receiving medicines through the Health Insurance Fund.

\section{Arguments against VAT reduction for medicines in Bulgaria}

The tax system must be neutral. VAT is not a tax intended to change consumer behavior. Such is the argument of the World Bank, which calls for comparable levels of taxation with other EU countries. Foods, despite their large differences, are not subject to increased cross-border trade due to their relatively low cost or low durability. With medicines, this factor is absent, but there are other informational and psychological barriers, such as the fact that most medicines are prescribed over the counter [3].

Reduced rates lead to fraud, hidden turnover, and development of the gray sector. This is the usual argument against the tax reduction in Bulgaria. The pharmaceutical sector is highly regulated and this argument is not particularly valid if institutions are working well. In addition, reducing the rate reduces the incentive for traders to hide turnover. Such an effect is less likely with medicines. VAT reductions will not affect prices or patients but will be absorbed by manufacturers and traders. It depends on the organization and competitiveness of the market, the presence of competition, good market regulations, etc. [8].

\section{Arguments to reduce the rate}

The prices of medicines in Bulgaria are one of the highest. From our chart, it is clear that we are at the forefront with one of the highest taxes in the EU. If VAT is reduced, at least part of drug prices will drop. However, there is reason to believe that more policy options have a bearing on drug policy. One of the most striking illustrations of its inefficiency is the fact that the prices for drugstore sales are often almost equal to what the patient has to pay after the partial rebate (reimbursement) borne by the NHIF $[10,13]$.

Patients in Bulgaria pay too much of their own money. These figures are also reported in the World Bank report - the share of pharmaceutical costs in our country reaches $38 \%$, compared to $25 \%$ on average in the 
EU. Accordingly, about $4 / 5$ of the drug costs are paid by the patient. Not only VAT is an explanation for this phenomenon. There are other factors such as public funds payments, NHIF policy and the Ministry of Health. Unfortunately, this tax has the greatest burden on the poor, the elderly and the sick [4].

\section{Discussion}

Now there is a big difference between increasing the interest of regulators in attracting the benefits of valueadded drugs and the resistance of tax-setting authorities who tend to overlook this important segment of the pharmaceutical field. This situation requires changes in policy to encourage appropriate incentives for recognizing the high value of medicines with the addition of tax and assessing the potential benefit to society. Policy changes should include: the absence of any legislative barriers to preventing VAT reductions; VAT requirements proportional to revenue; a VAT decision-making framework, taking into account the specific characteristics of medicines; eligibility for negotiation of VAT on medicines. Changes in pricing policy should include: tendering procedures / procurement policies; eligibility for different agreements; implementation of external and internal reference pricing policies; recognition of drug-specific pricing. At the same time, the pharmaceutical industry should engage all stakeholders (patients, healthcare providers, payers) in sentencing to set their expectations and to ensure that the change in value added tax on medicines meets their needs [11].

A number of medical aspects of health related to the irrational use of medicines, lack of appropriate treatment options, product shortages, geographical inequalities in access to medicines must be addressed. What is needed is improving the efficiency of the health care system and contributing to the sustainability of health care systems by reaping economic benefits.

\section{Conclusion}

Among the EU member states, Bulgaria applies one of the highest VAT rates on medicines. Given the low economic situation of our country, it is imperative that measures be taken to reduce its value. This is a prerequisite for improving the economic and health status of our population. It would be useful to introduce a differentiated VAT rate for prescription medicines.

\section{References}

1. Committee on Health, Forty-First National Assembly, Minutes, 07.06.2012.(in Bulgarian)

2. The latest EFPIA data on the VAT rates applied to medicines in European countries in 2018. https://pharmaboardroom.com/facts/vat-rates-on-medicine-in-europe-by-country-2018/

3. Nikolova D, Ganev P, FLAT TAX IN BULGARIA, background, introduction, results, Institute for Market Economics, 2016, 108. (in Bulgarian)

4. Lower VAT on Medicines - Pros and Cons, Economix, Aug. 24, 2015 https://economix.bg/ddsmedicines (in Bulgarian)

5. Consumption Tax Trends 2018: VAT/GST and excise rates, trends and policy issues. SecretaryGeneral of the OECD. 2016. doi:10.1787/ctt-2018-en. ISBN 978-92-64-22394-3.

6. Directive 2006/112/EC. https://eurlex.europa.eu/LexUriServ/LexUriServ.do?uri=OJ:L:2006:347:0001:0118:en:PDF

7. Directive 77/388/EC. https://eur-lex.europa.eu/legal-content/EN/TXT/?uri=LEGISSUM\%3AI31006 
8. EC Treaty, Article 249, paragraph 1.2

9. EU VAT returns - Avalara VATLive. https://www.vatlive.com/eu-vat-rules/eu-vat-returns/1

10. https://pharmaboardroom.com/facts/vat-rates-applicable-to-medicines/

11. https://www.statista.com/statistics/458957/vat-rate-on-prescription-only-drugs-in-europe/

12. Taxation and Customs Union -> Frequently Asked Questions. European Commission. Retrieved 2013

13. Toumi M, Rémuzat $C$, Value added medicines: what value repurposed medicines might bring to society?J Mark Access Health Policy. 2016 Dec 23;5(1):1264717. doi: 10.1080/20016689.2017.1264717. eCollection 2017.

14. VAT Notice 725 : the single market - GOV.UK

\section{Corresponding author:}

Vladimir Panov

Department of Conservative Dentistry and Oral Pathology, Faculty of Dental Medicine,Medical University, Varna;

e-mail: vladimir.panov@mu-varna.bg 